\title{
Comparative Clinico-pathological study of fine needle aspiration cytology and histopathology of various neck swellings in Bundelkhand region of Madhya Pradesh, India
}

\author{
Goswami R. ${ }^{1}$, Gangwani A. ${ }^{2}$, Shrivastava $P .^{3}$ \\ ${ }^{1}$ Dr. Reema Goswami, Associate Professor, Department of ENT, ${ }^{2}$ Dr. Amar Gangwani, Associate Professor, Department \\ of Pathology, ${ }^{3}$ Dr. Pranjal Shrivastava, Assistant Professor, Department of Community Medicine; All authors are \\ affiliated with Bundelkhand Medical College Sagar (M.P.) India.
}

Corresponding Author: Dr. Amar Gangwani, Associate Professor, Department of Pathology, Bundelkhand Medical College, Sagar, Madhya Pradesh, India. E-mail: drgangwaniamar79@gmail.com

\begin{abstract}
Introduction: Cervical swellings and lumps are common clinical problems. Neck swellings in children are commonly congenital and benign tumours while neck swellings in adults should be aimed to exclude malignancy. FNAC is the single most important test in the evaluation of neck swellings especially metastatic lymph nodes. FNAC helps in planning out surgical management of neck masses which can be confirmed with histopathology which is the gold standard for diagnosis. Objective: The aim of the study was to evaluate the various swellings in the neck and to compare the findings of FNAC and HPE. Material and Methods: The study is a prospective study conducted over a period of two years from January 2016 to January 2018 in the Department of ENT and Department of Pathology in Bundelkhand Medical College Sagar M.P. The study involved 100 cases of patients with neck swellings who attended ENT OPD and gave consent for both FNAC and biopsy or excision biopsy and HPE. Results: The overall accuracy of FNAC in diagnosing neck swellings is similar to that of HPE. Conclusion: FNAC is an important preoperative tool in the diagnosis of various neck swellings of the neck and is recommended as the first line of investigation in various neck swellings.
\end{abstract}

Keywords: Neck swellings, FNAC, HPE

\section{Introduction}

Many head and neck diseases manifests as neck swellings which can be of varying pathology from congenital neck masses to malignancies. Neck swellings in children are commonly congenital and benign while neck swellings in adults should be aimed to exclude malignancy [1]. Most patients can be diagnosed on the basis of a careful history and physical examination. Localized lymphadenopathy should prompt a search for an adjacent precipitating lesion and an examination of other nodal areas to rule out generalized lymphadenopathy. In general, lymph nodes greater than $1 \mathrm{~cm}$ in diameter are considered to be abnormal [2].

Supraclavicular nodes are the most worrisome for malignancy [2]. In most cases, a careful history and physical examination will identify a readily diagnosable

Manuscript received: $14^{\text {th }}$ May 2019

Reviewed: $24^{\text {th }}$ May 2019

Author Corrected: $30^{\text {th }}$ May 2019

Accepted for Publication: $6^{\text {th }}$ June 2019 cause of the neck swelling. Confirmation of the clinical diagnosis will need further diagnostic evaluation that includes, Fine needle aspiration cytology, biopsy, ultrasound, CT scan and MRI. Fine-needle aspiration (FNAC) is occasionally considered an alternative to excisional biopsy. FNAC is a less invasive, cost effective and time saving in comparison to histopathological examination. The current method for fine needle aspiration cytology was initially portrayed by Martin and Ellis in 1930 [3]. It was Koss in 1980 who said that "fine needle aspiration cytology is a methodology whose time has arrived" and the pathologists not adequately versed in the system will go under in pressure to provide it [4].

The aim of the study was to evaluate the various swellings in the neck and compare the findings of fine needle aspiration of neck swellings with histopathology of the swelling after excision or biopsy. 


\section{Material and Methods}

Study Design: A prospective study.

Setting: Study is conducted in the Department of Otorhinolaryngology and Pathology at Bundelkhand Medical College, Sagar, (M.P.)

Study Duration: 2 years from January 2016 to January 2018.

Sampling Method: The study is a Hospital based study and only patients attending the ENT OPD were included in the study through sequential sampling.

The study was conducted on 100 cases of neck swellings in all age groups and in both sexes.

Inclusion criteria: Patients giving consent for both preoperative FNAC and excision of swellings and postoperative histopathology of the excised specimen.

Exclusion criteria: Patients with neck abscess or open infected wounds and HIV positive patients.

Data collection procedure: After consent of the patient to participate in the study a detailed history was taken and complete general, systemic and local examination was carried out. In all cases a 20-25 gauze needle attached to a disposable $10 \mathrm{ml}$ syringe was used for
FNAC. The smears were prepared and stained with papanocolaou and examined for cellularity and cytomorphology of cell population.

After preoperative mandatory investigations including complete blood count, X-ray chest and ECG in adults, Thyroid function test and USG when required, the patients were taken up for surgery.

The excised specimen was sent for histopathology examination. The specimen was systematically formalin fixed, grossed and processed and stained by Haematoxylin and Eosin stain before histopathological reporting.

Data analysis: All collected data was entered in Microsoft excel and interpreted using SPSS 16.0.

The statistical significance was analysed using Mcnemar chi square test.

Kappa statistic was calculated for measurement of agreement. Sensitivity, specificity, positive predictive value and negative predictive value were calculated using $2 * 2$ tables and standard formulae.

Permission: Written consent was taken from all patients.

\section{Results}

In the present study of 100 cases of neck swellings 53 were female and 47 were male the male to female ratio being 1:1.3.

The age of patients ranged from 7 years to 70 years, the commonest age group being 21-30 years in 25 patients followed by 31 to 40 years in 22 patients.

Table-1: Age incidence.

\begin{tabular}{|c|c|c|}
\hline Age in years & No of patients & \% \\
\hline $1-10$ & 10 & 10 \\
\hline $11-20$ & 12 & 25 \\
\hline $21-30$ & 25 & 22 \\
\hline $31-40$ & 22 & 15 \\
\hline $41-50$ & 15 & 10 \\
\hline $51-60$ & 10 & 6 \\
\hline $61-70$ & 6 & 6 \\
\hline
\end{tabular}

About $50 \%$ of patients were in 21 to 40 years age group, while 21-30 years age group was commonest consisting of about $25 \%$ patients. 
Table-2: Type of neck swelling according to FNAC and HPE.

\begin{tabular}{|c|l|c|c|}
\hline S.No & \multicolumn{1}{|c|}{ Neck mass } & $\begin{array}{c}\text { Total according to HPE of } \\
\text { specimen }\end{array}$ & $\begin{array}{c}\text { No of cases where FNAC was } \\
\text { correct }\end{array}$ \\
\hline 1 & Dermoid cyst & 8 & 8 \\
\hline 2 & Sebaceous cyst & 23 & 4 \\
\hline 3 & Lipoma & 4 & 22 \\
\hline 4 & Metastatic deposits & 22 & 3 \\
\hline 5 & Non Hodgkins Lymphoma & 3 & 21 \\
\hline 6 & Nonspecific lymphadenitis & 24 & 3 \\
\hline 7 & Pleomorphic adenoma & 3 & 2 \\
\hline 8 & Chronic sialadenitis & 2 & 4 \\
\hline 9 & Thyroglossal cyst & 4 & 1 \\
\hline 10 & Lympangioma & 1 & 4 \\
\hline 11 & Colloid goitre & 4 & 2 \\
\hline 12 & follicular adenoma & 2 & 24 \\
\hline
\end{tabular}

Nonspecific lymphadenitis were most common neck swellings consisting of $24 \%$ of swellings followed by metastatic deposits (22\%) and sebaceous cyst (21\%).

Table-3: Diagnosed benign lesions on FNAC and HPE.

\begin{tabular}{|c|c|c|c|c|}
\hline \multirow{2}{*}{ FNAC } & \multicolumn{2}{|c|}{ HPE } & \multirow{2}{*}{ Total } & Mcnemar P value \\
\cline { 2 - 3 } \cline { 2 - 3 } & Benign positive & Benign negative & 71 \\
\cline { 2 - 3 } Benign positive & 71 & 01 & 03 & \multirow{2}{*}{0.625} \\
\hline Benign negative & 03 & 00 & $\mathbf{7 5}$ \\
\hline Total & $\mathbf{7 4}$ & $\mathbf{0 1}$ & \\
\hline
\end{tabular}

Out of 100 neck swellings 71 lesions were found to be benign on FNAC, while according to HPE 74 lesions were found to be benign. Three benign cases differed in diagnosis by FNAC \& HPE. These cases were diagnosed as Non specific Lymphadenitis on FNAC while on HPE they were diagnosed as Tubercular lymphadentis. Mcnemar test was applied and $\mathrm{P}$ value was found to be 0.625 which is non significant thus FNAC and HPE are comparable in correctly diagnosing benign lesions. The sensitivity of FNAC in correctly identifying benign lesions was $95.8 \%$ while positive predictive value was $98.3 \%$.

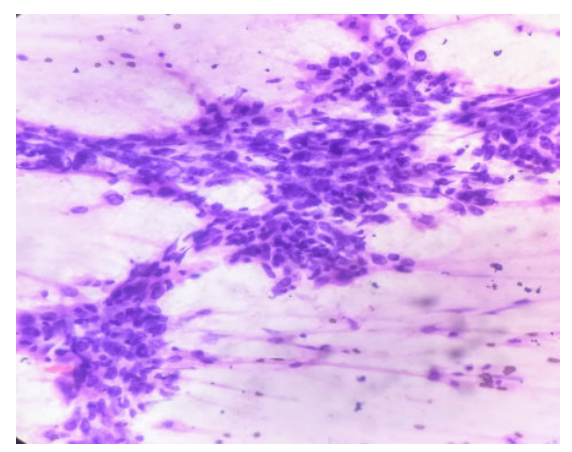

Fig-1: 40x Metastatic deposits of squamous cell carcinoma, cervical lymph node

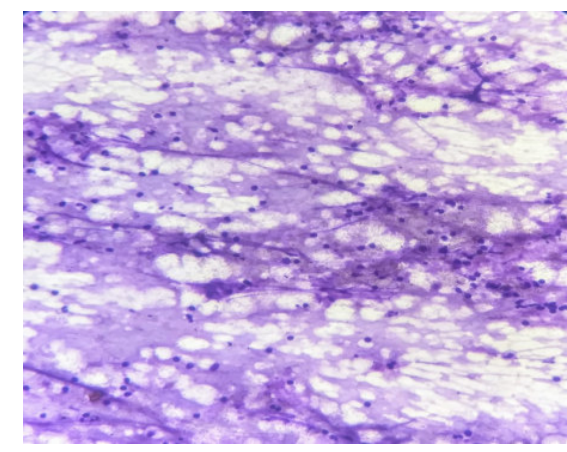

Fig-2: 40x Chronicnon specific lymphadenitis of cervical lymph node

Out of 100 cases, 94 cases had a positive correlation of FNAC with histopathological examination. Therefore the diagnostic accuracy of fine needle aspiration cytology in the present study was $94 \%$. 
The sensitivity, and specificity of FNAC in differentiating benign from malignant lesions in the present study was $100 \%$ [ $86.7 \%$ to $100 \%]$ and $100 \%$ [ $94.7 \%$ to $100 \%$ ] respectively Positive predictive value and Negative predictive value of FNAC in detecting malignancy were both $100 \%$ [86.7\% to $100 \%]$ and $100 \%$ [ $94.7 \%$ to 100$]$ respectively.

Interrater reliability using Kappa was measured between FNAC and Histopathology and a statistically significant measure of agreement was found $(\mathrm{k}=0.636, \mathrm{p}<0.05)$.

\section{Discussion}

A lump is the most likely clinical problem to be encountered in the neck. Lumps may be classified in relation to the triangles of the neck. The various triangles of the neck are Anterior, Digastric, Carotid, Muscular, and Posterior [5]. The anatomical knowledge of these triangles is very important for understanding the differential diagnosis of various pathologies presenting as neck swellings. The common pathologies encountered in the neck presenting as a lump are lymphadenopathies (specific and non-specific, acute and chronic), metastatic carcinoma, lymphoma, thyroid swellings (goitre, nodules and cysts) and salivary gland swellings (sialadenitis, cysts, adenomas and carcinomas). The less common pathologies presenting as swelling in the neck are carotid body tumour, branchial cyst, thyroglossal cyst, cystic hygroma, pharyngeal pouch and lumps of skin appendages $[5,6]$.

In the present study, 100 cases of neck swellings were studied over a period of 2 years. The maximum number of patients was in the age group of 21 to 30 years and the minimum age group was between 61 to 70 years. The results are similar to studies of $\mathrm{J}$ Jasani and $\mathrm{D}$ Taviad [7, 8]. The male to female ratio was 1.1.32. The results are similar to those of J Jasani and VK Poorey et al. who in their study also reported the number of females more than males. [7, 9].

Out of the total 100 cases of neck swellings 75 cases were non-neoplastic swellings while 25 cases were neoplastic. The above result is explained by the fact that tobacco chewing is prevalent in Bundelkhand region with Sagar District being one of the largest producers of tendu leaves and Beedi manufacturing was once the main source of income. Gertner et.al reported $71 \%$ cases non neoplastic and $29 \%$ cases neoplastic and Gupta $\mathrm{G}$ et al reported $75 \%$ cases non neoplastic while $25 \%$ cases neoplastic[10,11].

Thus our findings correlate with other studies. The FNAC involves study of cells obtained by fine needle under vacuum. Unlike biopsy, the whole tissue is not available for microscopic examination. Only cells are available for microscopic examination. Fine needle aspiration cytology offers a very simple and early method of diagnosis of neoplastic and non-neoplastic lesions of the neck. FNAC can be performed as an outpatient procedure. There is no need of anaesthesia speedy results are available and accurate diagnosis can be made. It serves as a preliminary complementary procedure to histopathological examination [12]. In the present study of out of 100 cases in the group of miscellaneous swellings which included 29 cases of benign cysts both dermoid and sebaceous cyst and 4 cases of lipoma. The results of pre-operative FNAC correlated with the HPE findings in 28 out of 29 cases. Swamy G et.al in their study also found similar results in their study of Lipoma [13]. The sensitivity specificity and accuracy of FNAC to detect benign cyst and lipoma in neck were $100 \%$. All the cases of congenital neck masses and lipoma were correctly diagnosed using FNAC in the present study with $100 \%$ diagnostic accuracy, which is similar to a study by Dejmek A et al[14].

In cases of enlarged lymph nodes, there were 24 cases of non-neoplastic lymph node and 25 cases neoplastic lymph nodes which were reported after FNAC. In the present study all cases of neck swellings where clinical diagnosis and FNAC were consistent for TB lymphadenitis, further lymph node biopsy was not performed andanti-tubercular drugs were started to prevent delay in treatment.All such cases excluded from the study. Out of 24 cases of non-neoplastic lymph nodes, in 21 cases both FNAC and HPE showed diagnosis of nonspecific lymphadenitis In 3 cases which showed nonspecific lymphadenitis on FNAC preoperatively lymph node biopsy reported it to be a tubercular lymph node.

The possible reason for missed diagnosis in the first instance may be non-representative lymph node selection from too peripherally situated lymph node rather than close to the centre of the lesion or crushing of the lymph node during surgery which destroys its morphology $[15,16]$. It may be initial non-specific response of a specific ailment [17].

Among the 25 neoplastic lymph nodes lesions 22 cases of enlarged lymph nodes presented with metastatic deposits of squamous cell carcinoma and 3 cases with non-Hodgkin's lymphoma on cytology. For the 


\section{Original Research Article}

metastatic lymph nodes evaluation for primary was done and biopsy was taken from the site and was proven to be squamous cell carcinoma on HPE. The goldstandard procedure for the diagnosis of a neck swelling is open biopsy of the swelling with histopathological examination of the excised tissue.

However, open biopsy of a metastatic cervical swelling prior to definitive treatment of the neck (usually by radical neck dissection) has been reported to lead a higher incidence of wound complications, regional neck recurrence and distant metastasis, than in patients who have no biopsy performed prior to definitive treatment $[18,19,20]$. The sensitivity of FNAC in diagnosis of metastatic lymph node is $100 \%$. Other authors have also reported similar results [21].

In 3 cases where FNAC showed non-Hodgkin's Lymphoma, excision biopsy of lymph node was done for HPE and immunopenotyping for classifying nonHodgkin's lymphoma. In the diagnosis of lymphoma FNAC can be used as a preliminary diagnosis which can be followed by histopathology and cytochemistry for confirmation [22].

In salivary gland lesions 3 cases presented with pleomorphic adenoma and 2 cases with chronic sialadenitis. In all the 5 cases salivary gland swellings the FNAC and HPE results were the same. J Jhansi reported $6 \%$ cases of salivary gland tumors in his study while $\mathrm{T}$ Ishar et al reported $9.3 \%$ cases in their study of neck swelling [7,23]. Sialadenitis was correctly diagnosed using FNAC with $100 \%$ diagnostic accuracy which is similar to a study by Viguer JM et al [24].

Among the 6 thyroid swellings 4 cases were of colloid goitre and 2 cases were of follicular neoplasm were reported on FNAC. After surgery HPE showed 4 cases of colloid goitre and 2 cases of follicular adenoma. All cases of Colloid goiters were correctly diagnosed, giving $100 \%$ accuracy, which is similar to a study by Jayaram G et al [25].

The limitation of the study was that most of the thyroid report to the surgery department. FNAC is, however, not without limitations; accuracy is lower in suspicious cytology and in follicular neoplasms. The main aim of FNAC is to identify nodules that require surgery and those benign nodules that can be observed clinically and decrease the overall thyroidectomy rate in patients with benign diseases. The present study was undertaken to correlate the FNAC findings with histopathology so that rate of unnecessary thyoidectomies in benign pathologies should be avoided.
In congenital lesions 4 cases presented with Thyroglossalcsyt and one case with Lymphangioma. In all cases the FNAC correlated with the HPE findings though in all these USG was performed preoperatively.

\section{Conclusion}

The overall sensitivity, specificity and accuracy of FNAC is very similar to histopathological examination. It is safe and reliable in the diagnosis of various neck swellings. However, it must never be thought as a replacement for histopathological diagnosis in all cases.

The two modalities have to complement each other, along with other newer diagnostic techniques for a diagnosis to be infallible and accurate for further management.

\section{Funding: Nil, Conflict of interest: Nil Permission from IRB: Yes}

\section{Reference}

1. Mc Guirt WF. The neck mass. Med Cli North Am. 1999;83(1):219-34.DOI: https://doi.org/10.1016/ S0025 - 7125(05)70098-5

2. Ferrer R. Lymphadenopathy: Differential diagnosis and evaluation. Am Fam Phy. 1998;58(6):1313-20.

3.Martin H. Aspiration biopsy [Internet]. CiNii Articles. 2019 [cited 12 July 2019].

4. Koss L. Thin needle aspiration biopsy (editorial).Acta Cytol. 1980;24(1-3).

5. Neck Masses [Internet]. Laurence Biro's reflections on Life, Universe and Everything. 2019 [cited 12 July 2019].

6.Miller D, Ervin T, Weichselbaum R, Fabian RL. The differential diagnosis of the mass in the neck.A fresh look.The Laryngoscope. 1981;91(1):140-5. DOI:https:// doi. org/10.1288/00005537-198101000-00021

7.Jasani JH, Vaishnani HV, Vekaria PN, Patel D, Shah Y, Savjiani N, Patel D, Lakhani D. Retrospective study of fine needle aspiration cytology of head and neck lesions in tertiary care hospital. IJBAR. 2013;4(4): 2536. DOI: https://doi.org/10.7439/ijbar.v4i4.337

8. Taviad D, Jadav K, Nikhra P, Panchal A, Patel V. Role of fine Needle aspiration cytology in head and neck swelling [Internet]. Semanticscholar.org. 2019 [cited 12 July 2019]. 
9. Poorey VK, Tyagi A. Accuracy of fine needle aspiration cytology in head and neck masses.Indian $\mathrm{J}$ Otolaryngol Head Neck Surg. 2014;66(2):182-6. DOI: 10.1007/s12070-014-0709-3. Epub 2014 Feb 14.

10. Gertner R, Podoshin L, Fradis M. Accuracy of fine needle aspiration biopsy in neck masses. The Laryngoscope.1984;94(10):1370-1.DOI: https://doi.org/ 10.1288/00005537-198410000-00020

11. Gupta G, Joshi DS, Shah A, Gandhi M, Shah NR. FNAC of head and neck swellings. GCSMC J Med Sci. 2014;3(1):38-41. DOI: http://dx.doi.org/10. 18203/issn. 2454-5929.ijohns 20175623

12. Shariff MA, Raju J. Fine Needle Aspiration Cytology, Neck mass, Histopathology. Accuracy of fine needle aspiration cytology in the diagnosis of neck masses. 2014;(3354).

13. Swamy GG., Chandrashekar B, Parameshwari: Comparison of Fine Needle Aspiration Cytology and Histopathology in the diagnosis of neck masses: Int $\mathrm{J}$ Recent Trends Sci Tech. 2013;6(1):13-16.

14. Dejmek A, Lindholm K. Fine needle aspiration biopsy of cystic lesions of the head and neck, excluding the thyroid.Acta Cytol. 1990;34(3):443-8.

15.Johnstone JMS, Msran, AGD, Rintoul RF. Opcratksns on malignant glands of the neck, in Fsrquharsons textbook of operative surgery. 7 th ed. Edinburgh, Churchill Livingstone, 1986;252-56

16. Russell, R.C.G. Lymph node biopsy, in atlas of general surgery. Edited by H. Dudley, D.C. Carter and RCG Russel $4^{\text {th }}$ edition Dutterworth.1986;28-9.

17. Greenfield S, Jordan MC. The clinical investigation of lymphadenopathy in primary care practice.JAMA.
1978;240(13):1388-93. DOI: 10.1001/jama.1978.03290 130082034

18. Alsamen AA, BasheerA, Rish KAA, Ebous AA, Abdallat M. JRMS 2010;17: 33-7.

19. Patt BS, Schaefer SD, Vuitch F. Role of fine-needle aspiration in the evaluation of neck masses.Med Clin NorthAm. 1993;77(3):611-23. DOI:https://doi.org / 10. 1016/ S0025-7125(16)30243-7.

20. JCDR - Search Back, Past Issue Volume Archive of Journal of Clinical and Diagnostic Research [Internet]. Jcdr.net. 2019 [cited 12 July 2019].

21. Wilkinson AR, Mahore SD, Maimoon SA. FNAC in the diagnosis of lymph node malignancies: A simple and sensitive tool. Official J Ind Soc Med Paediat Oncol. 2012;33(1):21.

22. Anne R Wilkinson, Sadhana D, Mahore, Sahiba A, Maimoon. FNAC in the diagnosis of lymph node malignancies: A simple and sensitive tool. Indian J Med Pediat Oncol. 2012; 5851. 9696433(1): 21-24.DOI: 10. 4103/ 0971

23. Ishar T, Gupta RK, Khajuria A. Role of FNAC in the diagnosis of non- thyroidal head and neck lesions. JK Sci; 2012:14:9-13

24. Viguer JM, Vicandi B, Jiménez-Heffernan JA, López-Ferrer P, Limeres MA. Fine needle aspiration cytology of pleomorphic adenoma. An analysis of 212 cases. Acta Cytol. 1997;41(3):786-94. DOI:10.1159/ 000332705

25. Jayaram G, Basu D. Cytology in the diagnosis of thyroid lesions. J Assoc Physicians India 1993; 41(3): 164-169.

\section{How to cite this article?}

Goswami R, Gangwani A, Shrivastava P. Comparative Clinico-pathological study of fine needle aspiration cytology and histopathology of various neck swellings in Bundelkhand region of Madhya Pradesh, India. Trop J Ophthalmol Otolaryngol.2019;4(2):157-162.doi:10.17511/jooo.2019.i02.15 